Send your letters to the Editor, British

Dental Journal, 64 Wimpole Street, London

W1G8YS E-mail bdj@bda.org

Priority will be given to letters less than 500

words long. Authors must sign the letter,

which may be edited for reasons of space.

\section{Incidental findings}

Sir, we would like to comment on the letter which purported to show the advantage of a thorough radiographic examination (BDJ 2006; 201: 689). Four panoramic radiographs of the same orthodontic patient are illustrated and the writer claims the benefit of these is that they show the development of an antral polyp.

The regulations concerning the use of radiographs, which were introduced in $2000,{ }^{1}$ place a responsibility on the practitioner only to take radiographs when there is a clinical indication. One of the reasons for the introduction of the new regulations is that there is no minimal acceptable dose of radiation, and as such every radiographic exposure must be clinically justified.

We fully appreciate that there are a number of chance incidental findings that can be demonstrated on radiographs but in the absence of symptoms, there is little benefit to the patient for the last two radiographs shown.

Radiographic exposure, 'just in case', is not justified. There has to be a sound clinical indication. A symptom-less antral polyp is not one of them.

K. G. Isaacson

\section{A. R. Thom}

Consultant Orthodontists Hampshire

1. Department of Health. The ionising radiation (medical exposure) regulations 2000. London: HMSO, 2000.

doi: 10.1038/bdj.2007.106

\section{External apical root resorption}

Sir, a 41-year-old Caucasian male presented with severe pain from his upper and lower right molars consistent with irreversible pulpitis. He had type 1 diabetes mellitus, which was poorly controlled, and vitiligo affecting his hands and feet (Fig. 1), and described previous episodes of transient thyroid abnormalities. A traveller of eastern European origin, he had received no orthodontic treatment in the past and although his brother also had type 1 diabetes mellitus, vitiligo and had lost his permanent dentition at an early age, the cause was unknown.

The patient had a minimally restored dentition, poor oral hygiene, supragingival and subgingival calculus, generalised gingivitis and 3-5 mm pocketing around the posterior teeth. The teeth were non-mobile and of normal clinical appearance although 17, 18 and 46 were extensively carious. An OPT radiograph showed external apical root resorption affecting all teeth, periapical areas associated with 17, 18 and 46 and calcification in several of the molar pulp chambers (Fig. 2).

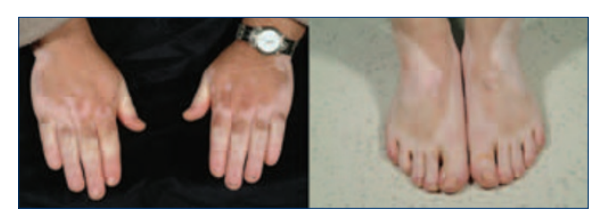

Fig. 1 Vitiligo affecting hands and feet

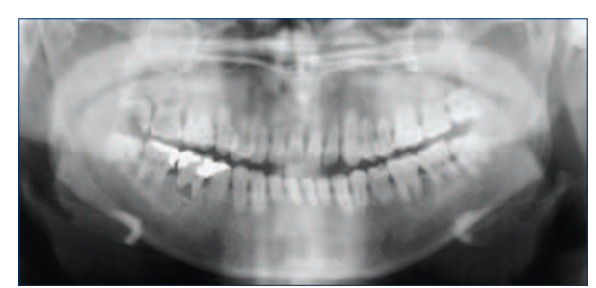

Fig. 2 Panoramic radiograph showing generalised external apical root resorption

Teeth 17, 18 and 46 were extracted under local anaesthesia and blood investigations were performed to identify any systemic causes. Full blood count, urea and electrolytes, liver function tests, bone biochemistry, thyroid function tests, parathyroid hormone, random blood sugar and an autoimmune screen were all within normal limits. The root resorption has remained static over a one year period. Long term follow up of his dentition in the form of radiographs and pulp testing is planned in liaison with his general dental practitioner. He continues to attend the endocrine medicine clinic.

External apical root resorption affecting multiple permanent teeth is rare with 14 reported cases in the literature. ${ }^{1}$ Only three of these cases report resorption affecting the entire

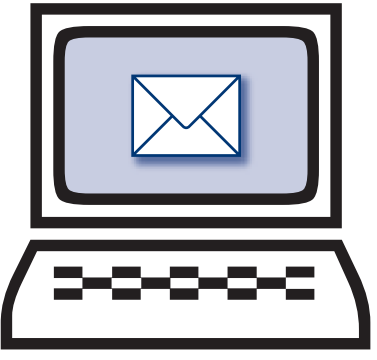

permanent dentition. Several systemic abnormalities have been associated with external root resorption, including Paget's disease, hypophosphataemia, hyperparathyroidism, bone dysplasia, Papillon-LeFèvre syndrome, renal disease, liver disease and Ehlers-Danlos syndrome Type VIII. ${ }^{1,2}$ However, no associated systemic condition was evident in the three previously reported cases affecting the entire permanent dentition. ${ }^{1}$ Genetic susceptibility to idiopathic external root resorption has been reported with autosomal dominant, autosomal recessive patterns and spontaneous phenotype demonstrated. ${ }^{2}$ Unfortunately the nature of his brother's tooth loss could not be confirmed and thus a genetic association is uncertain in this case.

The root resorption process involves complex interactions between inflammatory cells, resorbing cells, cytokines and enzymes. ${ }^{3}$ Changes in the host cellular immune system may be implicated in altering the resorption process and producing clinically significant external root resorption. ${ }^{4}$ Although not proven, this patient's type 1 diabetes mellitus and vitiligo are conditions associated with immunoendocrinopathy that may have caused sufficient change within the host cellular immune system to be the causative factor in his root resorption. As this combination of conditions may represent a new syndrome we are curious if it has been encountered elsewhere.

L. M. Carter
P. Hansrani

P. Hansr
York

S. Ferrier

Leeds

1. Cholia SS, Wilson PH R, Makdissi J. Multiple idiopathic external apical root resorption: report of four cases. Dentomaxilliofac Radiol 2005; 34: 240-246.

2. Newman W G. Possible etiologic factors in external root resorption. Am J Orthod 1975; 67: 552-539.

3. Ne R F, Witherspoon D E, Gutmann J L. Tooth Resorption. Quintessence Int 1999; 30: 9-25

4. Gunraj M N. Dental root resorption. Oral Surg Oral Med Oral Pathol Oral Radiol Endod 1999; 88: 647-653.

doi: 10.1038/bdj.2007.107 


\section{Diagnostic importance}

Sir, I would like to bring to the notice of all that the world has never seen a comparably complex public health hazard as that which it is currently experiencing in dealing with the effects of the AIDS epidemic on children. ${ }^{1}$ HIV infection was first recognised in children in $1983 .^{2}$ It has now assumed the proportions of a major public health challenge. Oral lesions are frequently among the first symptoms of HIV-infected children. Certain clinical findings typical of the disease in the paediatric age group are: salivary gland enlargement, pyogenic bacterial infections, developmental delay and dysmorphic craniofacial features.

Recognition of these early oral signs during routine examinations and in surgical procedures may allow for early intervention and a reduction in morbidity in the population. ${ }^{3}$ Clinicians involved with examination and treatment of the oral cavity must be aware of the potential for oral presentation of a wide variety of disseminated bacterial, parasitic and fungal infections in children who have AIDS or who are at high risk of contracting HIV. ${ }^{4}$

Three of the most common oral and extra-oral problems seen in children infected with HIV are thrush, cervical lymphadenopathy and parotitis. ${ }^{5}$ Oral manifestations should be considered the earliest clinical sign of HIV infection and a good indicator of the progression of HIV in children. Oral lesions can be asymptomatic or can present with pain, discomfort and eating restrictions. Oral examination is simple, quick and inexpensive. ${ }^{6}$ Early detection of HIV-related oral lesions can be used to diagnose HIV infection, elucidate progression of the disease, predict immune status, and provide a basis for more aggressive and appropriate treatment of HIV that may considerably improve the child's well being. ${ }^{1}$

Early and accurate diagnosis of oral lesions in children is an important component in their clinical management, as oral manifestations have been found to be the earliest indicators of HIV infection. Oral lesions are the source of substantial HIV-associated morbidity in both adults and children. In addition, certain oral lesions are markers for progressive immunologic dysfunction and HIV disease progression. For these reasons, careful and continuous assessment of oral health is an integral part of comprehensive HIV disease treatment.

In developing countries, where the techniques to diagnose and the drugs to treat HIV infection are not uniformly available, the use of oral lesions as predictors of disease progression could be of immense importance. Primary dental care for HIV infected children should include a careful oral examination at regular intervals to ensure early detection and intervention. Preventive oral health measures especially where treatment is unavailable, can improve a child's overall health.

Though such measures cannot stop the progression of HIV disease in the absence of medications, improved diagnosis of the oral manifestations of HIV infection can enhance case management, ensure better oral health outcomes and improve quality of life for HIV infected children. ${ }^{3}$ The treatment and eradication of HIV infection in children require major contributions from disciplines of nursing, social work and medicine.

Thus, all of us must develop at least a basic familiarity with this illness.

\section{Kamboj}

Lucknow

1. Naidoo S, Chikte U. Oro-facial manifestations in paediatric HIV: a comparative study of institutionalised and hospital outpatients. Oral Dis 2004; 10: 13-18.

2. Leggot PJ. Oral manifestations of HIV infection in children. Oral Surg Oral Med Oral Pathol 1992; 73: 187-192.

3. Ramos-Gomez FJ, Petru A, Hilton J F et al. Oral manifestations and dental status in paediatric HIV infection. Int J Paed Dent 2000; 10: 3-11.

4. Greenspan J S, Barr C E, Sciubba J J, Winkler J R. Oral manifestations of HIV infection. Definitions, diagnostic criteria and principles of therapy. The USA Oral AIDS Collaborative Group. Oral Surg Oral Med Oral Pathol 1992; 73: 142-144.

5. Pinkham J R C, Casamassimo PS, Fields $\mathrm{H}$ W et al. Introduction. In Pediatric dentistry: infancy through adolescence. WB Saunders, 2005.

6. Fallon J, Eddy J, Wiener L et al. Human immunodeficiency virus infection in children. J Pediat 1989; 114: 1-30.

10.1038/bdj.2007.108

\section{Dental thespians}

Sir, whilst it is very pleasing to see dentists taking an interest in those who treated teeth in the past, it would be even more so to see such interest placed within the wider context as, in this way, a much fuller and yet more interesting picture may be revealed.

Messrs Lynch, 0'Sullivan and MacGillycuddy's paper on Fauchard (Pierre Fauchard: the 'Father of Modern Dentistry', BDJ 2006; 201: 779-781) represented much of the little we know of this most interesting man, mostly according to those old stalwarts Viau, Hoffman-Axthelm and the redoubtable Lilian Lindsay. Once again, we see Fauchard presented as a man standing out from the charlatans of the marketplace, the majority of whom were, by implication, doing bad dentistry. Step back a bit, however, and the view widens to show that those 'charlatans' were doing something completely different - the business of performing. And by performing in public, aided by accomplices, they would be able to sell their many drugs and cures for the toothache, and other aches besides. ${ }^{1}$ Whilst they were doing this, however, surgeons in France were treading very fresh ground - that of specialisation within surgery, an activity which has been well documented more recently by such historians as Toby Gelfand, ${ }^{2}$ Colin Jones and Lawrence Brockliss, ${ }^{3}$ among others. A wider appreciation will show that Fauchard was not an isolated 'dentist', rejecting the rough techniques of his fellow practitioners with only the best interests of the public in mind. He was, rather, a clever and shrewd surgeon with an eye to the promotion of his new knowledge amongst the fashionable and influential of France and, no doubt, the furthering of his career alongside other newly-focused surgeons. Just 20 years before the publication of Fauchard's book, the revered general surgeon Pierre Dionis had written in some detail on the operations for the teeth within his Cours d'opérations de Chirurgie, ${ }^{4}$ one of the last 'general' surgical books to do so. And at the same time that Fauchard was writing his surgical book on the teeth only, the surgeon Julien Clément was being ennobled by Louis XIV for delivering royal offspring, setting the scene for the 'explosive arrival' of the socially desirable man-midwife or accoucheur. ${ }^{5}$ The chevalier Taylor, holding a degree from Reims, was also specialising in cutting for the cataract by the 1730s, taking the title of opticien or oculiste. The shrewd Fauchard, the rags-to-riches dentiste, was not alone.

\section{R. King}

By email

1. King R. Curing toothache on the stage? The importance of reading pictures in context. Hist Sci 1995; 33: 396-416

2. Gelfand T. Professionalizing modern medicine: Paris surgeons and medical science and institutions in the eighteenth century. Westport: Greenwood, 1980.

3. Brockliss L, Jones C. The medical world of early modern France. In The rise of surgery. Chapter 9. Oxford: Clarendon, 1997.

4. Dionis P. Cours d'opérations de Chirurgie, démontrées au Jardin Royal. Bruxelles: t'Serstevens et Claudinot, 1708.

5. King R. The making of the dentiste, c. 1650-1760. p 197. Aldershot: Ashgate, 1998.

10.1038/bdj.2007.109

\section{Value of electives}

Sir, the BDA Dental Academic Staff Group recently held a national workshop on the subject of student electives. Delegates were invited from all the UK dental schools, and other key dental decision makers including the President of the General Dental Council 
(GDC) attended. The stated objective of the meeting was to discuss whether to retain and develop dental student electives in the future, in particular to assess the current value of electives and to understand the learning outcomes that should be achieved by an elective or period of independent study.

Elective studies are specifically referred to in the GDC's document The first five years, upon which dental school curricula are based. The relevant paragraphs are:

'107. Students may gain useful educational experience outside the confines of the formal curriculum by participation in research projects under supervision or in elective programmes, whether in the United Kingdom or overseas.

'108. It is desirable, though not essential, for dental students to visit other dental schools or dental clinical centres, either in the United Kingdom or abroad, during the period of clinical study. The main objective should be to broaden the undergraduates' education by exploring the dental problems and dental management systems in another context. As far as possible, curricula should be designed to facilitate opportunities for elective studies. Elective visits might be arranged around a project consisting of either audit or research, and the results should be presented on return by students in written form or verbally before an audience.'

As the delegates from Glasgow Dental Hospital and School, we were surprised to learn that several UK schools have removed all elective programmes from their curriculum or are considering so doing. Two UK schools did not send a representative to the meeting. We would like to suggest, for wider discussion among the profession, that the elective programme forms an essential part of an undergraduate dental student's personal and professional development. This was certainly the impression given by the three student presentations on three quite different elective projects. Each speaker acknowledged that they had significantly developed in confidence, maturity and experience in a way that would have been impossible without this opportunity.

Given the clear benefits of the elective period on both a personal and professional level for these students, we were interested to note the intention of at least one UK school to essentially convert the elective programme to a period of formal research. Whilst the value of a background in research is important, the vast majority of undergraduates will be entering the general dental service and our feeling was that such a specific programme as an elective project added little to broadening the undergraduates' education for the majority of these students when compared with a wider based remit for elective study. It is acknowledged that an honours level degree programme must include an element of independent study, but does this have to be pure scientific research?

In our new, or 2004, curriculum at Glasgow we have chosen not only to retain the elective period, but to enhance it by broadening the range of experiences that our students may undertake. We also intend to include a number of student selected modules in the final year to enable the students to deepen their knowledge and experience of areas of particular interest - a time when formal research might be more appropriate. We are quite sure that by undertaking these experiences and reflecting on the outcomes our graduates will be better prepared for dental practice than those who simply follow a five year period of intensive academic study.

We hope that this letter will stimulate a wide debate and look forward with keen interest to the views expressed by our colleagues in both academic institutions and general practice.

P. Carrotte

By email

doi: $10.1038 /$ bdj.2007.110 